\title{
HEAT SHOCK PROTEINS IN AUTOIMMUNE DISEASES
}

\author{
Milan Raška, Evžen Weig1
}

\begin{abstract}
Department of Immunology, Faculty of Medicine, Palacky University in Olomouc, Czech Republic
E-mail: raskamil@hotmail.com
\end{abstract}

Received: June 10, 2005; Accepted: September 25, 2005

Key words: Heat shock protein/Autoimmunity/Hsp-immunization

Heat shock proteins (hsp's) are among the most conserved proteins in evolution. They have been identified as important pathogen-related antigens as well as autoantigens suitable for construction of novel vaccines. The high evolutionary homology of hsp's has raised the question about the safety of such vaccines. Experimental and clinical observations have confirmed that hsp proteins are involved in the regulation of some autoimmune disease such as autoimmune arthritis, type 1 diabetes mellitus, atherosclerosis, multiple sclerosis, and other autoimmune reactions. It has been shown in experimental animals that some hsp proteins (especially hsp60, hsp70, and hsp 10) can either induce or prevent autoimmune reactions depending on the circumstances.

This article discusses the involvement of hsp proteins in the etiology of autoimmune diseases and it presents promising experimental data on the effects of immunization with hsp proteins in the prevention and therapy of autoimmune diseases.

\section{ABBREVIATION}

AA, adjuvant arthritis; APC, antigen-presenting cells; hsp, heat shock protein; GAD, glutamic acid decarboxylase; GALT, gut-associated lymphoid tissues; grp, glucose regulating protein; IDDM, insulin-dependent diabetes mellitus; IFN- $\gamma$, interferon- $\gamma$; IL, interleukin; MHC major histocompatibility complex; NOD, non-obese diabetic mice; TcR, T cell receptor; TGF $\beta$, transforming growth factor $\beta$; TLR, Toll-like receptor.

\section{HSP INSIDE OF THE CELLS}

Heat shock proteins (hsp's) comprise a very heterogeneous group of proteins that can be divided into 6 families according to molecular weight: small hsp's (m.w. 12-43 kDa), hsp40, hsp60, hsp70, hsp90, and large hsp's (m.w. 100-110 kDa) ${ }^{1}$. Heat shock proteins belong to super family of stress proteins, which also comprise glucose regulating proteins (grp), ubiquitine and lectin chaperons - calnexin and calreticulin. The characteristic sign of the stress proteins is their overexpression during cellular stresses (high temperature, osmotic stress, UV, inflammation). Hsp's act as chaperons of nascent proteins (hsp60, hsp70, hsp40), protecting them from aggregation and improper folding, or as chaperons of intracellular signal proteins (hsp90, hsp40, hsp70), keeping them in an unstable substrate-grabable state ${ }^{2}$. Other members of hsp's proteins are participate in the protein degradation pathway (ubiquitin, hsp 104), driving damaged, abnormal, or abundant proteins to proteasome degradation ${ }^{3}$. Calreticulin, calnexin, and grp's are involved in the transport of an- tigens between TAP proteins (transporter associated with antigen processing) and major histocompatibility complex (MHC)(ref., $\left.{ }^{4,5}\right)$. Some SPs such as hsp90 and calreticulin have been confirmed to be tightly involved in morphogenesis ${ }^{6,7}$.

\section{HSP AS A "DANGER SIGNAL"}

An indispensable role of hsp proteins in intracellular processes explains their high evolutionary conservancy, which together with their overexpression during cellular stress makes them an important part of immune system recognition. Following their release from stressed microorganisms or from autologous inflamed or necrotizing tissue (tumors, target tissue of autoimmune diseases), hsp's may be recognized by the surface receptors of the cells of the host immune system (Toll-like receptor 4 - TLR-4, TLR-2, CD14, CD91, CD94, LOX-1, SR-A) or as an immunodominant antigen ${ }^{8-11}$. With the contribution of hsp proteins, the immune system is informed about the presence of internal pathologic processes. The high evolutionary conservancy of the bacterial hsp's and their overexpression during inflammation make them important antigens for host immune system ${ }^{4,11,12}$. Bacterial hsp-specific immune reaction (based mainly on $\mathrm{T}$ cell recognition) is rapid and highly effective and is permanently modulated by the presence of bacteria (especially normal gut flora)(ref. ${ }^{12-14}$ ). Thus any deviation in bacterial feedback signaling can be one of the factors involved in the etiology of autoimmune diseases. This article summarizes data from animal models of autoimmune diseases where hsp's play an important role in the induction of autoimmunity and/or setting of immune tolerance. 
The host immune response to microorganisms such as Borrelia burgdorferi, Chlamidia trachomatis, Helicobacter pylori, Mycobacterium leprae, M. tuberculosis, Yersinia enterocolitica, Leishmania donovani, Toxoplasma gondii, P. falciparum, Candida albicans, Trichophyton mentagrophytes and others) is associated with recognition of pathogen's hsp's ${ }^{15-26}$. During the inflammative immune response stressed host cell expressing hsp on their surface can be crossrecognized by the immune system. This association is described retrospectively in human medicine and thus it is not clear whether cross reactivity takes place in induction of autoimmune reaction ${ }^{12,27}$.

\section{HSP AND AUTOIMMUNITY}

In some autoimmune models immunization of experimental animals with killed bacteria or hsp peptides broke immune tolerance and indeed induced autoaggression. Immunization of mice with mycobacterial hsp60 induced crossreactive CD8 $\alpha / \beta$ T cells. These T cells recognized hsp60 peptides on MHC molecules in vitro and after transfer to $\alpha / \beta$ T cell-deficient mice these cells induced autoimmune disease with severe damage of the gut epithelium ${ }^{28}$. Experimental infection of mice with bacterium $M$. bovis BCG induced production of hsp60 reactive CD8 $\alpha / \beta \mathrm{T}$ cells $^{27}$. After stimulation with mycobacterium hsp60 peptides in vitro these hsp60-specific CD8 T cell recognized and lysed host cell exposed to thermal stress. Recognition and lysis was prevented when hsp60 expression was blocked in target cells with antisense nucleotides ${ }^{29}$. This experiment confirmed that the host immune system is able to induce autoreactive $\operatorname{CD} 8 \alpha / \beta$ T cell recognizing self hsp60 peptides ${ }^{27,29}$

Involvement of hsp's in the pathogenesis of autoimmune diseases has been studied using animal models such as: artificially induced arthritis (pristane, adjuvant arthritis, avridine induced arthritis, arthritis induced by streptococci cell wall and collagen type II induced arthritis)(ref. ${ }^{12,30-32}$ ) and insulin-dependent diabetes mellitus model (IDDM) in non-obese diabetic mice (NOD)(ref. ${ }^{33,34}$ ). The adjuvant arthritis (AA) model showed, for first time, that hsp60-specific T cells are not only proarthritogenic because the same epitope-recognizing $\mathrm{T}$ cells are also important for the setting of immune tolerance.

Animal models studying role of hsp's in autoimmune arthritis. AA is used as a model for rheumatoid arthritis or juvenile idiopathic arthritis since Pearson's first AA experiments ${ }^{35}$. Similarities between AA and rheumatoid arthritis comprise: 1. Synovial histopathological abnormalities, 2. Erosive polyarthritis. Similarities between AA and oligoarticular juvenile idiopathic arthritis comprise: 1. Synovial histopathological abnormalities, 2. Induction by a microbial agent, 3. Selfremitting course of disease, 4. Presence of uveitis, 5. Protective role of T cell reactivity to self $\mathrm{hsp}^{36-38}$.
The polyarthritis can be induced following a single intracutaneous injection with heat-killed Mycobacterium tuberculosis in incomplete Freund's adjuvant ${ }^{35}$ to susceptible rodents, such as Lewis, Buffalo, Sprague-Dawly and Wistar rats ${ }^{40}$. Interestingly, very young and old animals seem to be less susceptible to $\mathrm{AA}^{41}$. AA can be transferred from diseased animals to healthy naive animals with a single $\mathrm{T}$ cell clone specific for a particular sequence of $M$. tuberculosis hsp65. This finding supports the 'hit and run' hypothesis: "a microbial agent may pull the trigger and initiate a selfperpetuating autoimmune process in a susceptible individual" ${ }^{42}$. Detailed study of the $\mathrm{T}$ cell response has revealed two hsp-specific clones designated A2b and A2c. T cell clone A2b was strongly arthritogenic, while A2c was protective in AA. A2b and A 2c recognize the same epitope: a sequence derived from a $M$. bovis BCG hsp60, namely amino acid 180-188 (TFGLQLELT)(ref. ${ }^{36,37}$ ). The mechanism of the protective $T$ cell response is probably associated with crossrecognition of autologous hsp peptides. Hsp is readily available for synovial antigen-presenting cells (APC) which present hsp fragments on MHC to the specific T cells population. At present it seems that the self crossreactive antigen of the arthrogenic A2b T cell is rather than self hsp60 some still unknown epitope of the cartilage proteoglycan ${ }^{36,43}$. Exploring the whole human nonredundant protein databases (GenBank CDS translations, PDB, SwissProt, PIR, PRF) using BLAST-p software (http://www.ncbi.nlm.nih. gov) fail as well.

Experimental results indicate that the immune response against xenogenous hsp's is associated with induction of the protective as well as autoaggressive clones of specific $\mathrm{T}$ cell and the severity of disease is determined by interaction of both clones and many other factors. Concerning potential therapeutic benefits, the majority of experiments have been focused on induction of tolerance after immunization with hsp.

Protective effects of immunization with mycobacterium hsp65 was evaluated on $\mathrm{CBA} / \mathrm{Ig}^{\mathrm{h}}$ mouse model of pristane induced arthritis ${ }^{44}$. Pristane arthritis is autoimmune arthritis induced by i.p. application of pristane oil (2,6,10,14-tetramethyl-penta-decan). Pristane-induced arthritis is characterized by dominancy of Th1 response (elevated level of IFN- $\gamma$ and IL-2) after in vitro restimulation of arthritic mice splenocytes with mycobacterial hsp60. Mycobacterial hsp60 preimmunized mice were protected against Pristane arthritis. Isolated splenocytes response toward mycobacterial hsp65 stimulation in vitro by production of Th1 (IFN- $\gamma$ and IL-2) as well as Th2 (IL-4, IL-5 and IL-10) cytokines. Furthermore, in the same experiment the authors used IL-12 in a group of mice as an inductor of Th1 response. Application of the IL-12 abrogates protective effect of mycobacterial hsp60 immunization in Pristane arthritis. Furthermore, mycobacterial hsp60 immunization of mice induced preferentially IgG1 isotype of hsp60-specific antibody (Th2), in contrast to nonimmunized arthritogenic mice group with dominancy of IgG2a isolype (Th1)(ref. $\left.{ }^{44}\right)$. 
In another experiment immunization with entire mycobacterial hsp65 protects against collagen type II-induced arthritis, aviridine induced arthritis, and streptococcal cell wall-induced arthritis ${ }^{32,44,45}$.

Apart from the above mentioned mycobacterial hsp60 peptide 180 - 188 another protective peptide of mycobacterial hsp60 has been identified namely amino acid 256 - 270 (ALSTLVVNKIRGTFK)( ref. $^{46}$ ). Immunization of Lewis rats with mycobacterial hsp60 peptide M256 - 270 induced strongly autoproliferative but not cytotoxic $\mathrm{T}$ cells. This $\mathrm{T}$ cell clone after restimulation with peptide M256 - 270 responded to naive syngeneic APC in vitro by increased proliferation and production of IL-4, IL-10 and IFN- $\gamma$. The reaction was MHC II restricted. Exaggerated proliferation was observed when APC were heat-shocked before testing. Furthermore T cell expressed the cell-surface molecule B7.2. Contrary to high autoreactivity, these $\mathrm{T}$ cell clone induced reduction of AA elicited by i.d. application of heat killed mycobacteria (H37Ra) in incomplete Freund's adjuvant after transfer to mice. Increased expression of B7.2 molecule is associated with down regulation of specific $\mathrm{T}$ cell response due to interaction with another T cell-surface molecule CTLA-4. The suppressive interaction B7.2 - CTLA-4 is believed to be one of the most important protective mechanisms of autoreactive $\mathrm{T}$ cell clones in autoimmune diseases ${ }^{12,41,47,48}$. Along with the peptide 256 - 270 a highly evolutionary conserved core hsp60 peptide has been identified: mycobacerial 256 - 265 (ALSTLVVNKI), compare to rat hsp60 peptide 256 - 265 (ALSTLVLNRL)( ref. $^{46}$ ). Concerning the protective effect of $\mathrm{T}$ cell clones crossrecognizing autologous hsp 60 the question arises as to whether other highly conserved proteins, especially other hsp proteins, may act as protective antigens.

The mycobacterial hsp70 and hsp10 have been most studied $^{49-52}$. Immunizations of experimental rodents with highly conserved peptides of the mycobacterial hsp70 in the DDA adjuvant (dimethyl dioctadecyl ammonium bromide) did not confer assumed protective effects in the AA model ${ }^{53}$. However isolated T cells responding in vitro to the conserved $M$. tuberculosis hsp70 peptide namely amino acid 111 - 125 (ITDAVITTPAYFNDA) produced elevated levels of IL-10 $0^{53}$. The same T cell clone responded to rat hsp70 peptide 111 - 125 (VTNAVITVPAYFNDS). Recently DNA vaccination expressing human hsp70 or hsp90 has been shown to inhibit AA in Lewis rats ${ }^{51-52}$.

Mucosal intranasal low dose administration of protein antigen is generally associated with induction of $\mathrm{T}$ cells producing IL-10. Thus, the authors preimmunized the rats four times i.n. with the mycobacterial hsp70 peptide 111 - 125 and indeed achieved protection against subsequent induction of $\mathrm{AA}\left(\right.$ ref. $\left.^{53}\right)$.

IDDM and hsp's. Insulin-dependent diabetes mellitus is another example of hsp60 involvement in autoimmune diseases. IDDM is the clinical consequence of pancreas $\beta$-cell destruction by $\mathrm{T}$ cells. Infection of non-obese diabetic mice with $M$. avium prevents the development of diabetes $^{54}$. Similarly immunization of NOD mice with mycobacterial hsp60 significantly reduces the incidence of IDDM ${ }^{33}$. Furthermore adoptive transfer of a CD4 T cell clone specific for the mycobacterial hsp60 accelerated the onset of IDDM ${ }^{55}$. Although controversial, taken together with the fact that the $\beta$-cells of NOD mice showed elevated expression of hsp60 protein, hsp60 becomes a candidate autoantigen ${ }^{56,57}$. An epitope of the human hsp60 namely amino acid 277 - 300 (VLGGGCALL RCIPALDSLTPANED) was recognized by CD4 T cell clones isolated from NOD mice. After adoptive transfer, $\mathrm{T}$ cell clones produced profound insulitis in mice, but when gamma irradiated, the same $\mathrm{T}$ cells protected NOD mice against IDDM(ref. $\left.{ }^{55}\right)$. In another experiment human hsp60 peptide 277 - 300 treatment of NOD mice induces a Th2 cytokine burst ${ }^{58}$. Peptide 277 - 300 binds only to the TLR-2 on the T cells. Thus administering the peptide 277 - 300 causes a specific anti-inflammatory $T$ cell response without the induction of a pro-inflammatory macrophage response mediated through binding of hsp60 to TLR-4(ref. ${ }^{38,39}$ ). Recently, several studies have reported that the host immune response against $M$. tuberculosis hsp60 take place in chronic phase of infection and is described to be Th2 associated, contrary to early immune Th1 response specific to secreted bacilli proteins ${ }^{59}$. The above experiments suggest that hsp60 plays a principal role in the etiology of IDDM, but continuous research favors a $65 \mathrm{kDa}$ protein, glutamic acid decarboxylase (GAD) as a self antigen in both NOD mice and humans IDDM $^{60,61}$. NOD mice after immunization with GAD were protected against IDDM development ${ }^{61}$. GAD epitopes are recognized by $\mathrm{T}$ cell of NOD mice ${ }^{62}$. Three immunodominant GAD epitopes have been found namely amino acid 78 - 97 KPCSCSKVDVNYAFLHATDL, 202 - 221 TNMFTYEIAPVFVLLEYVTL, and 217 - 236 EYVTLKKMREIIGWPGGSGD. After administration to NOD mice the epitopes 78 - 97 and 202 - 221 induced Th1 response whereas epitope 217 - 236 induced Th2 response. Amino acid analysis of $M$. tuberculosis hsp60 and insulin motives presented on MHC II molecule, I-Ag7 (NOD homologue of HLA-DQB1) confirmed that GAD peptide 202 - 221 contains the same anchor consensus $\mathrm{V} / \mathrm{YXVXXE}^{62}$. Although undoubtedly involved in IDDM etiology, the above-mentioned antigens such as GAD, hsp60 and insulin cannot cause IDDM sensitive or resistant phenotype. Recently Tian et al demonstrate on NOD mice that the IDDM sensitive phenotype is determined by the amino acid composition of MHC II molecule that may affect the ability of this molecule to mediate the negative selection of autoreactive T cells during ontogenesis ${ }^{63}$.

\section{NON $\alpha / \beta$ T CELLS MECHANISMS OF HSP'S INVOLVEMENT IN AUTOIMMUNE DISEASES}

Not only the $\alpha / \beta$ T cells are involved in target tissue destruction. Other mechanisms such as $\gamma / \delta$ T cells, Natural killer cells, APC, and specific antibodies have been confirmed to participate in autoimmune diseases ${ }^{27,46,64-67}$. $\gamma / \delta \mathrm{T}$ cells were found in autoimmune plaques in multiple sclerosis and they have been colocalized with oligodendroglial cells expressing hsp. These $\gamma / \delta$ T cells act as cytotoxic ${ }^{68}$. 
Crossreacting hsp-specific antibodies were confirmed in the sera of patients with chronic granulomatous bowel disease (m. Crohn). Human hsp60-recognizing antibodies crossreact with mycobacterial hsp60 analog. Mycobacteria, especially low pathogenic species, are considered as an inductive factor in Crohn's disease ${ }^{69}$. Species-specific hsp60-recognizing antibodies have been confirmed during infection with $B$. burgdorferi, $C$. trachomatis. Antibodies crossrecognized human hsp $60^{28,65}$. Anti-hsp 70 antibodies have been found in the sera of patients with malaria ${ }^{70}$. In patients with lupus erythematodus increased expression of the hsp90 on the surface of peripheral lymphocytes and monocytes as well as increased level of serum anti-hsp90 antibodies were detected ${ }^{11,71,72}$.

The positive role of the hsp-specific immune crossreactivity, which is probably evoked by low pathogenic or gut commensal bacteria, may enable the already prepared immune system to react quickly before the immune response to more pathogen-specific antigens develops ${ }^{28,73}$.

\section{THREE MECHANISMS HOW HSP-SPECIFIC T CELLS CONTRIBUTE TO IMMUNE TOLERANCE}

Hsp-specific T cells contribute to long-lasting autotolerance and prevent autoimmune diseases by several mechanisms:

1) Bystander antiinflammatory effects of lymphocytes educated in GALT mainly through IL-10. Gut-associated lymphoid tissues (GALT) are continuously confronted with components of food and gut microflora to which long-term immune tolerance establishment is essential ${ }^{74}$. Antiinflammatory cytokines, such as IL-10 and TGF- $\beta$ are produced not only by cells of the adaptive immune system but also, as in the case of IL-10, by intestinal epithelial cells ${ }^{41}$. Subsequently, whenever confronted with the homologues present in mammalian hsp overexpressed in the inflamed joint (or other organ) immigrating GALT cells control inflammation through bystander suppressive effects $^{12,41}$.

Another mechanism - oral tolerance - is effective in inhibiting adjuvant arthritis induction in rats. Low doses of antigen administration favor the induction of active cellular regulation, e.g. by release of the antiinflammatory cytokines TGF- $\beta$, IL-4, and IL-10, whereas higher doses favor clonal anergy or deletion ${ }^{75}$. In animal models, feeding Lewis rats with mycobacterial hsp60 in the presence of soybean trypsine inhibitor reduced significantly the severity of ongoing AA. Moreover, isolated splenocytes respond in vitro to hsp60 stimulation by IL-10 production ${ }^{76}$. More recently, atherosclerosis and inflammation have been shown to be reduced by mucosal administration of mycobacterial hsp60 in mice ${ }^{77,78}$. Experimental allergic encephalomyelitis can be prevented in the mouse by prior administration of myelin basic protein or copolymer 1 , which simulates myelin basic protein immunologically ${ }^{75,79}$. In human trials, the administration of autoantigens has not yet yielded successful therapy ${ }^{79}$. The concomitant generation of antigen-specific cytotoxic T cells possibly accounts for this failure. Choosing the adequate antigen, the adequate dose, and manipulation of the antigen-presenting dendritic cells are strategies that can be used to overcome the remaining obstacles ${ }^{79}$.

2) The low affinity $T c R$ recognition of self hsp peptide leads to suppression of inflammatory $T$ cell response through B7.2 - CTLA-4 interaction.

The cells can present peptides derived from hsp60 through MHC I or MHC II. Such cells may be target for cytotoxic $\alpha / \beta$ T cells ${ }^{28,80}$. Cytotoxic T cells are considered main ethio-pathologic factor, although, many experiments confirmed that hsp-specific $\alpha / \beta$ T cells are involved only in advanced disease ${ }^{28}$. Crossreacting hsp70-specific T cells were found in humans with tuberculosis and leprosis ${ }^{81}$. In IDDM patients, the hsp60 reactivity of the $\alpha / \beta$ T cells is considered as the secondary effect of the autoreactivity against the dominant autoantigen, the GAD $\left(\right.$ ref. $\left.^{62}\right)$. In $Y$. enterocolitica-triggered reactive arthritis, hsp60-specific synovial CD $4 \alpha / \beta$ T cells crossreact with human hsp60 protein, heat stressed APC, and synovial mononuclear cells in vitro ${ }^{82}$. Moreover autologous hsp60-specific $\mathrm{T}$ cells were identified in Bechcet disease ${ }^{83,84}$, rheumatoid arthritis ${ }^{85}$, juvenile rheumatoid arthritis, and juvenile chronic arthritis $^{82,86}$.

Only a partial homology is required for the $\alpha / \beta$ $\mathrm{T}$ cell TcR crossrecognition of peptides presented on the MHC I molecule. In contrast, the amino acid motifs involved in anchoring the peptides in particular MHC I groove have to be identical in the full spectrum of corresponding MHC I presented peptides ${ }^{29}$. The amino acid differences between microbial and self hsp may play a crucial role. In thymic areas involved in positive selection hsp's are expressed among others. Positively selected T cells show a low affinity for self, including selfhsp60. Those low affinity $\mathrm{T}$ cells that recognize conserved epitopes, could expand after contact with microbial homologues and $\mathrm{T}$ cells with a relatively high affinity for the microbial homologues prevail. Arising T cells pool can still recognize the self hsp epitopes with relatively low affinity. $\mathrm{T}$ cells from Lewis rats (immunized with mycobacterial hsp60 peptide M256 - 270) upregulate B7.1 and B7.2 after in vitro stimulation with mycobacterial hsp60 peptide (256 - 265) in dose dependent manner. In case of low peptide concentration only B7.2 expression was observed. Contrary, the same T cells after stimulation with rat 256 - 265 peptide (as an altered peptide ligand) responded by selective upregulation of only B7.2 molecule independently on peptide concentration used ${ }^{46,47}$. Thus high affinity peptide recognition (in high dose conditions) is coupled with proinflammatory (Th1) T cell response (situation during infection) whereas lowered affinity recognition (independently on dose), promote a response in the direction of a Th2 or regulatory response ${ }^{41,47}$. The described antiinflammatory phenotype is probably linked with the selective B7.2 - CTLA-4 interaction of T cells-expressed B7.2 molecule which interacts only with CTLA-4 but not with CD28, contrary to B7.2 on APC(ref. $\left.{ }^{46,47}\right)$. Observed selectivity is probably linked with the different glycosyla- 
tion of B7.2. The antiinflammatory feedback associated with the action of altered peptide ligands ( such as hsp) is permanently induced by the presence of low virulent bacteria probably by mechanism of low dose stimulation observed in the mycobacterial hsp60 256 - 265 peptide $^{37,47}$. Thus paradoxically, long-lasting germ free conditions can contribute to development of the autoimmune process ${ }^{87}$.

Conserved regions of the hsp's comprise the target antigens also for $\gamma / \delta$ T cells whose participation in early phase of infections caused by Listeria monocytogenes, Plasmodium yoelii and Leishmania major ${ }^{27}$. In newborn mice were confirmed thymic $\gamma / \delta$ T cells recognizing mycobacterial hsp60 peptides as well as homologous mammalian hsp60 peptides ${ }^{13,14}$. Those $\gamma / \delta$ T cells may contribute to autoimmunity ${ }^{28}$. Experiments with minimized mycobacterial hsp60 peptides recognized by $\gamma / \delta$ TcR did not confirm cross reactivity with mammalian analogous peptides ${ }^{88}$. Furthermore, in vitro experiments confirmed, that all $\gamma / \delta$ $\mathrm{T}$ cells expressing $\mathrm{V} \gamma 1$ chain recognizes the same minimal peptide. The hsp peptides are supposed to bind conserved regions of $\mathrm{V} \gamma 1$ chain and not hypervariable $\mathrm{V} \gamma 1$ domains. The meaning of these in vitro observations remains to be elucidated. Otherwise hsp70-specific $\gamma / \delta$ T cells elicited during protozoan and/or intracellular bacterial infections showed weak interspecies hsp70 crossreactivity and occasionally hsp70-specific $\gamma / \delta \mathrm{T}$ cells recognized unique species-specific hsp70 epitope. Beside the $\gamma / \delta$ T cells, another cell type - dendritic cells - use pathogen hsp to fight against infection. Dendritic cells recognize the pathogen hsp through surface receptors (TLR-4)(ref. ${ }^{8,89}$ ).

3) Nonprofessional APC presentation of hsp epitopes without costimulatory molecules drives $\mathbf{T}$ cell to anergy.

The ubiquitous low level of constitutive hsp expression in every cell of the body will guarantee that $\mathrm{T}$ cells will notice the presence of self hsp epitopes also on nonprofessional APC that lack the costimulatory molecules needed to induce the $\mathrm{T}$ cell response. Recognition in the absence of proper costimulation is known to drive $\mathrm{T}$ cells into a state of anergy ${ }^{12,41}$.

\section{ACKNOWLEDGEMENT}

We acknowledge the support by grant IGA MZCR NI7538-3/2003. We thank to Dr. Jan Novak and Stacy Hall for critical reading of the manuscript.

\section{REFERENCES}

1. Weigl E, Kopeček P, Raška M, Hradilová Š. (1999) Heat shock proteins in immune reactions. Folia Microbiologica 44, 561-6.

2. Hartl FU, Hayer-Hartl M. (2002) Molecular chaperones in the cytosol: from nascent chain to folded protein. Science 295, 1852-8.

3. Mathew A, Mathur SK, Morimoto RI. (1998) Heat Shock Response and Protein Degradation: Regulation of Hsf2 by the UbiquitinProteasome Pathway. Mol Cell Biol 18, 5091-8.

4. Berwin B, Nicchitta CV. (2001) To find the road traveled to tumor immunity: the trafficking itineraries of molecular chaperones in antigen-presenting cells. Traffic 2, 690-7.
5. Vambutas A, DeVoti J, Pinn W, Steinberg BM, Bonagura VR. (2001) Interaction of human papillomavirus type 11 e7 protein with tap-1 results in the reduction of atp-dependent peptide transport. Clin Immunol 101, 94-9.

6. Murphy-Ullrich JE. (2001) The de-adhesive activity of matricellular proteins: is intermediate cell adhesion an adaptive state? J Clin Invest 107, 785-90.

7. Rutherford SL, Lindquist S. (1998) Hsp90 As a Capacitor For Morphological Evolution. Nature 396, 336-42.

8. Ohashi K, Burkart V, Flohe S, Kolb H. (2001) Cutting edge: heat shock protein 60 is a putative endogenous ligand of the toll-like receptor-4 complex. J Immunol 164, 558-61.

9. Basu S, Binder RJ, Ramalingam T, Srivastava PK. (2001) CD91 is a common receptor for heat shock proteins gp96, hsp90, hsp70, and calreticulin. Immunity 14, 303-13.

10. Srivastava PK, Jaikaria NS. (2001) Methods of purification of heat shock protein-peptide complexes for use as vaccines against cancers and infectious diseases. Methods Mol Biol 156, 175-86.

11. Quintana FJ, Cohen IR. (2005) Heat shock proteins as endogenous adjuvants in sterile and septic inflammation. J Immunol 175 , 2777-82.

12. van Eden W, van der Zee R, Prakken B. (2005) Heat-shock proteins induce T-cell regulation of chronic inflammation. Nat Rev Immunol 5, 318-30.

13. O’Brien RL, Fu YX, Cranfill R, Dallas A, Ellis C, Reardon C, Lang J, Carding SR, Kubo R, Born W. (1992) Heat shock protein hsp60-reactive gamma/delta cells. A large, diversified T-lymphocyte subset with highly focused specificity. Proc Natl Acad Sci USA 89, 4348-52.

14. Born W, Hall L, Dallas A, Boymel J, Shinnick T, Young D, Brehnan P, O’Brien RL. (1990) Recognition of a peptide antigen by heat shock reactive gamma/delta T lymphocytes. Science 249, 67-9.

15. Himeno K, Hisaeda H. (1996) Contribution of 65-kDa heat shock protein induced by gamma delta $\mathrm{T}$ cells to protection against Toxoplasma gondii infection. Immunol Res 15, 258-64.

16. Hansen K, Bangsborg JM, Fjordvang H, Pedersen NS, Hindersson P. (1988) Immunochemical characterization of, and isolation of the gene for Borrelia burgdorferi immunodominant 60-kilodalton antigen common to a wide range of bacteria. Infect Immun 56, 2047-53.

17. Danilition SL, Maclean IW, Peeling R, Winston S, Brunham RC. (1990) The 75-kilodalton protein of Chlamydia trachomatis: a member of the heat shock protein 70 family. Infect. Immun 58 , 189-96.

18. Morrison RP, Belland RJ, Lyng K, Caldwell HD. (1989) Chlamydial disease pathogenesis. The $57-\mathrm{kD}$ chlamydial hypersensitivity antigen is a stress response protein. J Exp Med 170, 1271-83.

19. Ferrero RL, Thilberge JM, Kansau I, Wuscher N, Huerre M, Labigne A. (1995) The GroES homolog of Helicobacter pylori confers protective immunity against mucosal infection in mice. Proc Natl Acad Sci USA 92, 6499-503.

20. Yamakoshi M, Taguchi H, Yoshida M. A Chaperonin from Thermophilic Bacterium Thermus thermopilus. In: AF Fink, Y Goto (Eds). Molecular Chaperones in the Life Cycle of Proteins Marcel Dekker Inc, New York 1998. p. 301-2.

21. Garsia RJ, Hellqvist L, Booth RJ, Radford AJ, Britton WJ, Astbury L, Trent RJ, Basten A. (1989) Homology of the 70-kilodalton antigens from Mycobacterium leprae and Mycobacterium tuberculosis 71-kilodalton antigen and with the conserved heat shock protein 70 of eucaryotes. Infect Immun 57, 204-12.

22. Bonato VLD, Lima VMF, Tascon RE, Lowrie DB, Silva CL. (1998) Identification and Characterization of Protective T Cells in hsp65 DNA-Vaccinated and Mycobacterium tuberculosis-Infected Mice. Infect Immun 66, 169-75.

23. Noll A, Rogenkamp A, Heesemann J, Autenrieth IB. (1994) Protective role for heat shock protein-reactive ab T cells in murine yersiniosis. Infect Immun 62, 2784-91.

24. Jendoubi M, Bonnefoy S. (1988) Identification of a heat shock-like antigen in P. falciparum, related to the heat shock protein 90 family. Nucleic Acids Res. 16, 10928-31. 
25. Raska M, Rybnikar A, Chumela J, Belakova J, Weigl E. (2004) Recombinant protein and DNA vaccines derived from hsp60 protein Trichophyton mentagrophytes control the clinical course of trichophytosis in bovine species and guinea pigs. Mycoses 47, 407-17.

26. Raska M, Belakova J, Wudattu NK, Kafkova L, Ruzickova K, Kolar Z, Weigl E. (2005) Comparison of protective effect of protein and DNA vaccines hsp90 in murine model of systemic candidiasis. Folia Microbiologica 50, 77-82.

27. Zủgel U, Kaufmann SHE. (1997) Activation of CD8 T cells with specificity for mycobacterial heat shock protein 60 in Mycobacterium bovis bacillus Calmette-Gue'rin-vaccinated mice. Infect Immun 65, 3947-50.

28. Zủgel U, Kaufmann SHE. (1999) Role of Heat Shock Proteins in Protection from and Pathogenesis of Infectious Diseases. Clin Microb Rev 12, 19-39.

29. Steinhoff U, Zügel U, Hengel H, Rösch R, Munk ME, Kaufmann SHE. (1994) Prevention of autoimmune lysis by T cells with specificity for a heat shock protein by anti-sense oligonucleotide treatment. Proc Natl Acad Sci USA 91, 5085-8.

30. Billingham MEJ, Carney S, Butler R, Collston MJ. (1990) A mycobacterial heat shock protein induces antigen-specific suppression of adjuvant arthritis, but is not itself arthritogenic. J Exp Med 171, 339-44.

31. Thompson SJ, Rook GAW, Brealey RJ, van der Zee R, Elson CJ. (1990) Autoimmune reactions to heat-shock proteins in pristaneinduced arthritis. Eur J Immunol 20, 2479-84.

32. van den Broek MF, Hagervorst EJM, van Bruggen MCJ, van Eden W, van der Zee R, van den Berg WB. (1989) Protection against streptococcal cell wall-induced arthritis by pretreatment with the 65-kD mycobacterial heat shock protein. J Exp Med 170, 44966.

33. Elias D, Markovits D, Reshef T, van der Zee R, Cohen IR. (1990) Induction and therapy of autoimmune diabetes in the non-obese diabetic $(\mathrm{NOD} / \mathrm{Lt})$ mouse by a $65-\mathrm{kDa}$ heat shock protein. Proc Natl Acad Sci USA 87, 1576-80.

34. Shimada A, Kasatani T, Takei I, Maruyma T, Nomaguchi H, Ozawa Y, Ishii M, Kasuga A, Tashiro F, Miyazaki J, Yamamura K, Saruta T. (1996) Immune response to heat-shock protein correlates with induction of insulitis in I-E alpha transgenic NOD mice. Diabetes 45, 165-9.

35. Pearson CM. (1956) Development of arthritis, periarthritis and periostitis in rats giving adjuvant. Proc Soc Exp Biol Med 91, 95-101.

36. van Eden W, Hauet-Broere F, Berlo S, Paul L, van der Zee R, de Kleer I, Prakken B, Taams L. (2005) Stress proteins as inducers and targets of regulatory T cells in arthritis. Int Rev Immunol 24, 181-97.

37. van Eden W, Wendling U, Paul L, Prakken B, van Kooten P, van der Zee R. (2000) Arthritis protective regulatory potential of selfheat shock protein cross-reactive T cells. Cell Stress Chaperones 5, 452-7.

38. Raz I, Eldor R, Naparstek Y. (2005) Immune modulation for prevention of type 1 diabetes mellitus. Trends in Biotechnology 23, 128-34.

39. Raz I, Elias D, Avron A, Tamir M, Metzger M, Cohen IR. (2001) $\beta$-cell function in new-onset type 1 diabetes and immunomodulation with a heat-shock protein peptide (DiaPep277). a randomised, double-blind, phase II trial. Lancet 358, 1749-53.

40. Waksman BH. (2002) Immune regulation in adjuvant disease and other arthritis models: relevance to pathogenesis of chronic arthritis. Scand J Immunol 56, 12-34.

41. van Eden W, Waksman BH. (2003) Immune Regulation in Adjuvant-Induced Arthritis Possible Implications for Innovative Therapeutic Strategies in Arthritis. Artritis Rheumatism 48, 17881796.

42. Cohen IR, Holoshitz J, van Eden W, Frenkel A. (1985) T lymphocyte clones illuminate pathogenesis and affect therapy of experimental arthritis. Arthritis Rheum 28, 841-5.

43. van Bilsen JH, Wagenaar-Hilbers JP, Boot EP, van Eden W, Wauben MH. (2002) Searching for the cartilage-associated mimicry epitope in adjuvant arthritis. Autoimmunity 35, 201.
44. Beech JT, Siew LK, Ghoraishian M, Stasiuk LM, Elson CJ, Thompson SJ. (1997) CD4+ T cells specific for mycobacterial 65-kilodalton heat shock protein protect against pristane induced arthritis. J Immunol 159, 3692-7.

45. Bendele A, Sennello G, McAbee T. (1999) Effects of interleukin 1 receptor antagonist alone and in combination with methotrexate in adjuvant arthritic rats. J Rheumatol 26, 1225.

46. Paul AGA, van Kooten PJS, van Eden W, van der Zee R. (2000) Highly Autoproliferative T Cell Specific for $60 \mathrm{kDa}$ Heat Shock Protein Produce IL-4/IL-10, IFN-gamma and Are Protective in Adjuvant Arthritis. J Immunol 165, 7270-7.

47. Paul AGA,van der Zee R,Taams LS, van Eden W. (2000) Aselfhsp60 peptide acts as a partial agonist inducing expression of B7-2 on mycobacterial hsp60-specific T cells: a possible mechanism for inhibitory $\mathrm{T}$ cell regulation of adjuvant arthritis? Int Immunol 12, 1041-50.

48. Krummel MF, Allison JP. (1995) CD28 and CTLA-4 have opposing effects on the response of T cells to stimulation. J Exp Med $182,459-65$.

49. Kingston AE, Hicks CA, Colston MJ, Billingham ME. (1996) A 71$\mathrm{kD}$ heat shock protein (hsp) from Mycobacterium tuberculosis has modulatory effects on experimental rat arthritis. Clin Exp Immunol $103,77-82$.

50. Tanaka S. (1999) Activation of T cells recognizing an epitope of heatshock protein 70 can protect against rat adjuvant arthritis. $\mathrm{J}$ Immunol 163, 5560-5.

51. Quintana FJ, Carmi P, Mor F, Cohen IR. (2004) Inhibition of adjuvant-induced arthritis by DNA vaccination with the 70 -kd or the 90-kd human heat-shock protein. immune cross-regulation with the 60-kd heat-shock protein. Arthritis Rheum 50, 3712-20.

52. Quintana FJ, Cohen IR. (2005) DNA vaccines coding for heatshock proteins (HSPs). tools for the activation of HSP-specific regulatory T cells. Expert Opin Biol Ther 5, 545-54.

53. Wendling U, Paul L, van der Zee R, Prakken B, Singh M, van Eden W. (2000) A conserved mycobacterial heat shock protein (hsp) 70 sequence prevents adjuvant arthritis upon nasal administration and induces IL10-producing T cells that cross-react with the mammalian self-hsp70 homologue. J Immunol 164, 2711-7.

54. Bras A, Aguas AP. (1996) Diabetes-prone NOD mice are resistant to Mycobacterium avium and the infection prevents autoimmune disease. Immunology 89, 20-5.

55. Elias D, Reshef T, Birk OS, van der Zee R, Walker MD, Cohen IR. (1991) Vaccination against autoimmune mouse diabetes with a T-cell epitope of the human $65-\mathrm{kDa}$ heat shock protein. Proc Natl Acad Sci USA 88, 3088-91.

56. Brudzynski K, Martinez V, Gupta RS. (1992) Immunocytochemical localization of heat-shock protein 60 -related protein in beta-cell secretory granules and its altered distribution in non-obese diabetic mice. Diabetologia 35, 316-24.

57. Brudzynski K, Martinez V, Gupta RS. (1992) Secretory granule autoantigen in insulin-dependent diabetes mellitus is related to the $62 \mathrm{kDa}$ heat-shock protein (hsp60). J Autoimmun 5, 453-63.

58. Elias D, Meilin A, Ablamunits V, Birk OS, Carmi P, KoenenWaisman S, Cohen IR. (1997) Hsp60 peptides therapy of NOD mouse diabetes induces a Th2 cytokine burst and downregulates autoimmunity to various beta-cell antigens. Diabetes 46, 758-64.

59. Jiao X, Lo-Man R, Winter N, Deriaud E, Gicquel B, Leclerc C. (2003) The shift of Th1 to Th2 Immunodominance Associated with the Chronicity of Mycobacterium bovis Bacille Calmette-Guerin Infection Does Not Affect the Memory Response. J Immunol 170, 1392-8.

60. Atkinson MA, Kaufman DL, Campbell L, Gibbs KA, Shah SC, Bu DF, Erlander MG, Tobin AJ, MacIaren NK. (1992) Response of peripheral-blood mononuclear cells to glutamate decarboxylase in insulin-dependent diabetes. Lancet 339, 458-9.

61. Tisch R, Yang X-D, Singer SM, Liblau RS, Fugger L, McDevitt HO. (1993) Immune response to glutamic acid decarboxylase correlates with insulitis in non-obese diabetic mice. Nature 366, 72-5.

62. Zechel MA, Elliott JF, Atkinson MA, Singh B. (1998) Characterization of novel T-cell epitopes on $65 \mathrm{kDa}$ and $67 \mathrm{kDa}$ glutamic acid decarboxylase relevant in autoimmune responses in NOD mice. J Autoimmun 11, 83-95. 
63. Tian C, Bagley J, Cretin N, Seth N, Wucherpfennig KW, Iacomini J. (2004) Prevention of type 1 diabetes by gene therapy. J Clin Invest 114, 969-78.

64. Multhoff G, Botzler C, Jennen L, Schmidt J, Ellwart J, Issels R. (1997) Heat shock protein 72 on tumor cells. a recognition structure for natural killer cells. J Immunol 158, 4341-50.

65. Shanafelt MC, Hindersson P, Soderberg C, Mensi N, Turck CW, Webb D, Yssel H, Peltz G. (1991) T cell and antibody reactivity with the Borrelia burgdorferi $60-\mathrm{kDa}$ heat shock protein in lyme arthritis. J Immunol 146, 3985-92.

66. Kleindienst R, Xu Q, Willeit J, Waldenberger FR, Weimann S, Wick G. (1993) Immunology of atherosclerosis. Demonstration of heat shock protein 60 expression and $\mathrm{T}$ lymphocytes bearing alpha/beta or gamma/delta receptor in human atherosclerotic lesions. Am J Pathol 142, 1927-37.

67. Shimonkevitz R, Colburn C, Burnham JA, Murray RS, Kotzin BL (1993) Clonal expansion of activated gamma/delta T cells in recentonset multiple sclerosis. Proc Natl Acad Sci USA 90, 923-7.

68. Freedman MS, Buu NN, Ruijs TC, Williams K, Antel JP. (1992) Differential expression of heat shock proteins by human glial cells. J Neuroimmunol 41, 231-8.

69. Peetermans WE. Expression of and immune response to heat shock protein 65 in Crohn's disease. In: van Eden W, Young DB, editors. Stress proteins in medicine. Marcel Dekker Inc, New York 1996. p. 197-1.

70. Mattei D, Ozaki LS, Pereira da Silva L. (1988) A Plasmodium falciparum gene encoding a heat shock-like antigen related to the rat 78 kD glucose-regulated protein. Nucleic Acids Res 16, 5204-8

71. Erkeller-Yueksel FM, Isenberg DA, Dhillon VB, Latchman DS, Lydyard PM. (1992) Surface expression of heat shock protein 90 by blood mononuclear cells from patients with systemic lupus erythematosus. J Autoimmun 5, 803-14.

72. Faulds GB, Isenberg DA, Latchman DS. (1994) The tissue-specific elevation in synthesis of $90 \mathrm{kD}$-heat shock protein precedes the onset of disease in lupus-prone MRL/lpr mice. J Rheumatol 21, 234-8.

73. Kaufmann SHE, Schoel B. Heat shock proteins as antigens in immunity against infection and self. In: Morimoto RI, Tissieres A, Georgopoulos C, editors. The biology of heat shock proteins and molecular chaperones. Cold Spring Harbor Laboratory Press, Cold Spring Harbor, 1994. p. 495-531.

74. Wills-Karp M, Santeliz J, Karp CL. (2001) The germless theory of allergic disease: revisiting the hygiene hypothesis. Nat Rev Immunol 1, 69-75.

75. Weiner HL. (2000) Oral tolerance, an active immunologic process mediated by multiple mechanisms. J Clin Invest 106, 935-7.

76. Cobelens PM, Heijnen CJ, Nieuwenhuis EES, Kramer PPG, van der Zee R, van Eden W, Kavelaars A. (2000) Treatment of adjuvant-induced arthritis by oral administration of mycobacterial hsp65 during disease. Arthritis Rheum 43, 2694-702.
77. Harats D, Yacov N, Gilburd B, Shoenfeld Y, George J. (2002) Oral tolerance with heat shock protein 65 attenuates Mycobacterium tuberculosis-induced and high-fat-diet-driven atherosclerotic lesions. J Am Coll Cardiol 40, 1333-8.

78. Maron R, Sukhova G, Faria AM, Hoffmann E, Mach F, Libby P, Weiner HL. (2002) Mucosal administration of heat shock protein65 decreases atherosclerosis and inflammation in the aortic arch of low-density lipoprotein receptor-deficient mice. Circulation 106, $1708-15$.

79. Kweon MN, Kiyono H. (2002) CD40L in autoimmunity and mucosally induced tolerance. J Clin Invest 109, 171-3.

80. Jardetzky TS, Lane WS, Robinson RA, Madden DR, Wiley DC. (1991) Identification of self peptides bound to purified HLA-B27. Nature 353, 326-9.

81. Anderton SM, van der Zee R, Goodacre JA (1993) Inflammation activates self hsp60-specific T cells. Eur J Immunol 23, 33-8.

82. E, Lohse AW, van der Zee R, van Eden W, Mayet W, Probst P, Poralla T, Meyer zum Buschenfelde KM, Fleischer B. (1991) Synovial fluid-derived Yersinia-reactive $\mathrm{T}$ cells responding to human $65-\mathrm{kDa}$ heat-shock protein and heat-stressed antigen-presenting cells. Eur J Immunol 21, 2139-43.

83. Lehner T, Childerstone A, Pervin K, Hasan A, Direskeneli H, Stanford MR, Whiston R, Kasp E, Dumonde DC, Shinnick T, van der Zee R, Mizushima Y. Stress proteins in Bechet's disease and experimental uveitis. In: van Eden W, Young DB, editors. Stress proteins in medicine. Marcel Dekker Inc, New York 1996. p. 16383.

84. Pervin K, Childerstone A, Shinnick T, Mizushima Y, van der Zee R, Hasan A, Vaughan R, Lehner T. (1993) T cell epitope expression of mycobacterial and homologous human 65-kilodalton heat shock protein peptides in short term cell lines from patients with Behcet's disease. J Immunol 151, 2273-82.

85. Li SG, Quayle AJ, Shen Y, Kjeldsen-Kragh J, Oftung F, Gupta RS, Natvig JB, Forre OT. (1992) Mycobacteria and human heat shock protein-specific cytotoxic $\mathrm{T}$ lymphocytes in rheumatoid synovial inflammation. Arthritis Rheum 35, 270-81.

86. De Graeff-Meeder ER, van der Zee R, Rijkers GT, Schuurman HJ, Kuis W, Bijlsma JWJ, Zegers BJM, van Eden W. (1991) Recognition of human $60 \mathrm{kD}$ heat shock protein by mononuclear cells from patients with juvenile chronic arthritis. Lancet 337, $1368-72$.

87. Gaston JSH. (1997) Heat Shock Proteins and Arthritis - New Readers Start Here. Autoimmuity 26, 33-42.

88. Fu YX, Kersh G, Vollmer M, Kalataradi H, Heyborne K, Reardon C, Miles C, O’Brien RL, Born W. (1994) Structural requirements for peptides that stimulate a subset of gamma/delta $\mathrm{T}$ cells. $\mathrm{J}$ Immunol 152, 1578-88.

89. Cho BK, Palliser D, Guillen E, Wisniewski J, Young RA, Chen J, Eisen HN. (2000) A proposed mechanism for the induction of cytotoxic T lymphocyte production by heat shock fusion proteins. Immunity 12, 263-72. 